Article

\title{
Sodium and Potassium Intakes and Their Ratio in Adults (18-90 y): Findings from the Irish National Adult Nutrition Survey
}

\author{
Eoin Morrissey ${ }^{1,+}$, Miriam Giltinan ${ }^{2,+}$, Laura Kehoe $^{2}{ }^{(D}$, Anne P. Nugent ${ }^{3,4}(\mathbb{D}$, \\ Breige A. McNulty ${ }^{3}$, Albert Flynn ${ }^{2}$ and Janette Walton ${ }^{1,2, *}$ \\ 1 Department of Biological Sciences, Cork Institute of Technology, T12928 Cork, Ireland; \\ eoin.morrissey@mycit.ie \\ 2 School of Food and Nutritional Sciences, University College Cork, T12 K8AF Cork, Ireland; \\ miriamgiltinan@gmail.com (M.G.); laura.kehoe@ucc.ie (L.K.); a.flynn@ucc.ie (A.F.) \\ 3 UCD Institute of Food and Health, University College Dublin, Belfield, D04 V1W8 Dublin, Ireland; \\ A.Nugent@qub.ac.uk (A.P.N.); breige.mcnulty@ucd.ie (B.A.M.) \\ 4 Institute for Global Food Security, School of Biological Sciences, Queens University Belfast, \\ Belfast BT7 1NN, Northern Ireland, UK \\ * Correspondence: janette.walton@cit.ie; Tel.: +353-(0)21-4326195 \\ $\dagger$ Both authors contributed equally to the manuscript.
}

Received: 27 February 2020; Accepted: 26 March 2020; Published: 28 March 2020

check for updates

\begin{abstract}
An individual's sodium to potassium intake ratio (Na:K) has been shown to be an important predictor of hypertension. The aim of this study was to estimate the mean $24 \mathrm{~h}$ urinary $\mathrm{Na}, \mathrm{K}$ and $\mathrm{Na}: \mathrm{K}$ of Irish adults and to identify the foods that determine $\mathrm{Na}: \mathrm{K}$ in a nationally representative sample of Irish adults. This study was based on data from the Irish National Adult Nutrition Survey (2008-2010) (NANS), which collected spot urine samples and dietary data in a nationally representative sample of Irish adults aged $18+$ years. The mean urinary molar Na:K of Irish men and women was 1.90 and 2.15 , respectively, which exceed target molar ratios of $\leq 1.0$ and $\leq 2.0$. The mean estimated 24-h urinary excretion of Na was $4631 \mathrm{mg}$ for men and $3525 \mathrm{mg}$ for women, which exceed target maximum population intakes for all gender and age groups. The mean estimated 24-h urinary excretion of $\mathrm{K}$ was $3894 \mathrm{mg}$ for men and $2686 \mathrm{mg}$ for women, with intakes in women of all ages and older men (65+ years) below current recommendations. The key foods positively associated with a lower Na:K were fruits, vegetables, potatoes, breakfast cereals, milk, yogurt and fresh meat, while the foods negatively associated with a lower Na:K were breads, cured and processed meats and butters and fat spreads. Strategies to reduce sodium and increase potassium intakes are necessary to lower population Na:K, which may help to reduce the burden of hypertension-related diseases in the Irish population.
\end{abstract}

Keywords: sodium; salt; potassium; sodium to potassium ratio; hypertension

\section{Introduction}

A diet low in sodium $(\mathrm{Na})$ and high in potassium $(\mathrm{K})$ is widely recommended as a strategy to lower blood pressure and to reduce the risk of cardiovascular disease (CVD), as high blood pressure (hypertension) is a primary risk factor for CVD [1]. CVD is one of the leading causes of morbidity and mortality in the world, accounting for one-third of deaths both in Ireland and globally [2]; hence, efforts to reduce the proportion of the population with hypertension are of great public health importance.

The European Food Safety Authority (EFSA) has set an adequate intake (AI) for sodium of $2.0 \mathrm{~g} / \mathrm{d}$ (equivalent to $5 \mathrm{~g} / \mathrm{d}$ salt) for adults of all ages, based on a sufficient requirement to maintain 
sodium balance and at levels associated with a reduced risk of CVD [3]. While meeting the AI for sodium is considered beneficial for health, the Food Safety Authority of Ireland (FSAI) and the UK Scientific Advisory Committee on Nutrition (SACN) have set target maximum population salt intakes of $<6 \mathrm{~g} / \mathrm{d}[4,5]$. With regard to potassium, the EFSA has set an AI of $3.5 \mathrm{~g} / \mathrm{d}$ for adults of all ages [6], based on studies showing the blood pressure lowering effects of potassium, with intakes below $3.5 \mathrm{~g} / \mathrm{d}$ being associated with a higher risk of stroke [7].

While the individual effects of sodium and potassium on blood pressure have been long established, there is a consensus that an individual's sodium to potassium intake ratio (Na:K) is a more important predictor of hypertension than either sodium or potassium intake alone $[1,8,9]$. This hypothesis is supported by a large body of evidence including findings from INTERSALT; a large world-wide epidemiological study (consisting of over 10,000 adults aged 20-59 years across 32 countries). This study found that reductions in $\mathrm{Na}: \mathrm{K}$ had a greater effect on reducing blood pressure than the individual effects of sodium or potassium alone and suggested that lowering of population $\mathrm{Na}: \mathrm{K}$ would lead to reductions in blood pressure that would enable significant reductions in CVD and mortality rates [9]. For individuals, the World Health Organisation (WHO) recommend a sodium intake $<2000 \mathrm{mg} / \mathrm{d}$ and a potassium intake $>3510 \mathrm{mg} / \mathrm{d}[10,11]$, which would yield a Na:K of $\leq 0.6 \mathrm{mg} / \mathrm{mg}(\leq 1.0 \mathrm{mmol} / \mathrm{mmol}$ measured by urinary excretion). This ratio of intake is considered beneficial for health and has also been related to a reduction in stroke risk [11,12]. While a molar Na:K $\leq 1.0$ is preferable, compliance to this recommendation is low and recent studies have shown that molar intake ratios between 1.0 and 2.0 may lower CVD risk in adults [13-18]. Therefore, a molar intake ratio $\leq 2.0$ has been suggested as a suboptimal goal to lower blood pressure [19].

Measuring urinary excretion of sodium and potassium from multiple $24 \mathrm{~h}$ urine collections is considered the gold standard method of measuring an individual's Na:K [20]. However, for large-scale studies collecting 24-h urine can be costly and time consuming [21]. Therefore, many studies collect spot urine samples which can be used to estimate the $24 \mathrm{~h} \mathrm{Na:K} \mathrm{[22]} \mathrm{in} \mathrm{addition} \mathrm{to} \mathrm{population} \mathrm{sodium}$ and potassium intakes [23]. INTERSALT has estimated Na:K from $24 \mathrm{~h}$ urine collections and reported a mean molar Na:K ranging from 0.01 (Yanomamo, Brazil) to 7.58 (Tianjin, China), with the mean molar Na:K of Western populations estimated to be 2.98 [22]. Individual cross-sectional studies of adults have reported a mean molar Na:K ranging from 2.2 to 3.8 across studies, with Na:K greater than 2.0 in all study groups [13-18]. The INTERSALT study has also shown that reductions in the mean population urinary Na:K from 3.09 to 1.0 would result in a reduction of population blood pressure of such size ( $3-5 \mathrm{mmHg}$ ) to reduce stroke mortality by $8 \%-14 \%$, CHD mortality by $5 \%-9 \%$ and all-cause mortality by $4 \%-7 \%$ [9]. The Irish National Adult Nutrition Survey (2008-2010) (NANS) is the most recent study to collect urinary excretion data for $\mathrm{Na}$ and $\mathrm{K}$, in addition to detailed dietary intake data for both nutrients in a nationally representative sample of adults in Ireland. The objective of the following study was to use these data to estimate mean $24 \mathrm{~h}$ excretions of sodium, potassium and Na:K in a nationally representative sample of Irish adults. An additional aim was to identify food groups which determine a higher or lower dietary Na:K in Irish adults.

\section{Materials and Methods}

\subsection{The National Adult Nutrition Survey (NANS) Sample}

A detailed description of the methodology used in NANS has been reported elsewhere [24,25]. Briefly, the fieldwork phase of NANS was carried out between October 2008 and April 2010, providing a seasonal balance to the data and biological sample collection. A quota sampling approach was adopted using data from the 2006 Irish Census [26] to achieve a nationally representative sample. Eligible participants were community-dwelling adults aged 18 years and over who were not pregnant or lactating. The study was conducted according to the guidelines laid down in the declaration of Helsinki and all procedures involving human participants were approved by the Clinical Research Ethics Committee of the Cork Teaching Hospitals, University College Cork and the Human Ethics 
Research Committee of University College Dublin (ethical approval code: Ref.: ECM 3 (p) 04/11/08). Written informed consent was obtained from all eligible and willing participants. The final response rate for the survey was $60 \%$. Analysis of the demographic features in this sample has shown it to be a representative sample of Irish adults with respect to age, gender, social class and geographical location when compared to Census data [26]. While participation in the survey did not require provision of a urine sample as an eligibility criterion, all participants were asked whether they were willing to provide one, and $75 \%$ ( $n$ 1121) provided a sample.

\subsection{Urine Sample Collection, Processing and Analysis}

Participants were provided with a sterile container to collect a first void urine sample (minimum, $20 \mathrm{~mL}$; aim, $50 \mathrm{~mL}$ ) and instructed to fast for $12 \mathrm{~h}$ prior to obtaining the sample. An icepack was also provided to keep the sample chilled until same day collection by the researcher. Samples were transported to laboratories at University College Cork or University College Dublin, where they were processed and stored at $-20^{\circ} \mathrm{C}$ until analysis. Urine samples were typically obtained either at the same time as the 4 days of dietary assessment or within a 2-week period. Urinary $\mathrm{Na}$ and $\mathrm{K}$ were measured by the Randox Rx Daytona with an ion-selective electrode. The quality control material used was Randox QC urine with assigned values for $\mathrm{Na}$ and $\mathrm{K}$, which were measured at both low and high levels. The quality assurance used was the Randox International Quality Assessment Scheme. The interassay coefficient for $\mathrm{Na}$ was $\leq 5.0 \%$ and for $\mathrm{K}$ was $\leq 4.1 \%$.

\subsection{Food Consumption Data}

A 4-day semi-weighed food diary was used to collect food and beverage intake data. Participants ( $n=1500)$ were visited by a trained fieldworker three times during the recording period inclusive of one detailed training session prior to study commencement. Participants were asked to record detailed information (at the brand level) on the types and amounts of all foods, beverages and nutritional supplements consumed over the 4-day period. Details of recipes, leftovers, and (where applicable) cooking method used were also recorded. Participants were also encouraged to keep food labels to provide further information on the nutrient composition of the consumed foods. A hierarchal method [27] was used to quantify the amount of each food/beverage consumed. This included direct weighing of the food by participants, provided by manufacturer's information, use of a photographic food atlas [28], standard food portion sizes [29] and household measures.

Intakes of energy, sodium and potassium were estimated using WISP ${ }^{\odot}$ nutritional analysis software which includes data from McCance and Widdowson's 'The Composition of Foods' sixth edition [30] and supplemental volumes [31-39]. Modifications to this nutrient database were carried out at the time of the survey and included addition of all nutritional supplements, fortified foods, recipes and generic Irish foods that were recorded during the survey period [40]. Sodium values were updated using analytical data provided by the Food Safety Authority of Ireland and current manufacturer's information at the time of the survey (derived from product labels). For dietary analyses, salt added at the table or in recipes was not accounted for. For foods that may be cooked in salted or unsalted water such as vegetables and pasta, the default of 'boiled in unsalted water' was used.

\subsection{Data Analyses}

\subsubsection{Urinary}

Mean $24 \mathrm{~h}$ excretions of sodium and potassium intake were estimated by correcting the mean $\mathrm{Na}$ and $\mathrm{K}$ concentrations in the spot urine samples for gender-specific 24-h urine volume estimations for Irish adults derived from a study by Perry et al. [41] which has been shown to provide adequate population-level estimates of sodium and potassium intakes [23]. The 24-h Na excretions were compared to the EFSA AI of $2.0 \mathrm{~g} / \mathrm{d}$ [3] and the 24-h K excretions were compared to the EFSA AI of 
$3500 \mathrm{mg} / \mathrm{d}$ [7]. Urinary molar Na:K was calculated for each participant as $\mathrm{Na}(\mathrm{mmol} / \mathrm{L}) / \mathrm{K}(\mathrm{mmol} / \mathrm{L})$, with a value of 0.6 being subtracted from each individual value to correct for timing bias associated with circadian rhythms [42]. Compliance with Na:K target molar ratios was examined by assessing the proportion of the population complying with the WHO guideline of $\leq 1.0$ and the suggested suboptimal target of $\leq 2.0[11,19]$.

\subsubsection{Dietary}

Usual intake distributions of sodium and potassium and dietary molar Na:K were estimated using the validated National Cancer Institute (NCI) method [43] using SAS Enterprise Guide ${ }^{\circledR}$ Version 6.1 (SAS Institute Inc., Cary, NC, USA). The NCI method has been implemented in SAS macros (version 2.1) which were downloaded from the website www.riskfactor.gov/diet/usualintakes/macro.html (date of download: July 2015). SPSS Version 21 for Windows ${ }^{\mathrm{TM}}$ (SPSS, Inc.) was used for all further dietary analyses. The key sources of sodium and potassium were calculated by the mean proportion method as defined by Krebs-Smith et al. [44]. This method provides information about the sources that are contributing to the nutrient intake "per person" and is the preferred method when determining important food sources of a nutrient for individuals in the population group as opposed to investigating the sources of a nutrient within the food supply. The contribution of discretionary salt to total salt intake in the Irish population was crudely estimated for each gender and age group (18-35, 36-50, 51-64 and 65+ years) by examining the difference between mean dietary sodium intake and mean urinary sodium excretion. Dietary molar Na:K was calculated for each individual as the mean daily intake of sodium (excluding discretionary salt) divided by the mean daily intake of potassium. In order to examine the foods/food groups that are associated with a lower dietary Na:K in Irish adults, the population was divided into thirds (low, medium, high) according to their dietary Na:K (stratified by gender and age group). Differences in intakes of sodium, potassium, dietary Na:K and food group intakes between participants with low and high Na:K were assessed using a Mann-Whitney $U$ test and Kruskal-Wallis test (for non-normally distributed data). To minimise type 1 errors (as a result of multiple testing), the Bonferroni adjustment was used, and therefore intakes were considered to be statistically different if $P<0.001$.

\section{Results}

\subsection{Urinary Data}

Table 1 describes the mean $24 \mathrm{~h}$ urinary excretions of $\mathrm{Na}$, salt equivalents, $\mathrm{K}$, urinary molar $\mathrm{Na}: \mathrm{K}$ and prevalence of urinary Na:K $\leq 1.0$ and $\leq 2.0$ in Irish adults based on first void spot urine samples corrected for gender-specific population $24 \mathrm{~h}$ urine volume estimations. The mean 24 -h urinary excretion of $\mathrm{Na}$ was $4631 \mathrm{mg}$ for men and $3525 \mathrm{mg}$ for women, equivalent to a salt excretion of $11.6 \mathrm{~g}$ for men and $8.8 \mathrm{~g}$ for women, which are higher than the EFSA AI of $2.0 \mathrm{~g} / \mathrm{d}$ for sodium (salt equivalent: $5 \mathrm{~g} / \mathrm{d})$ and target maximum population salt intakes $(<6 \mathrm{~g} / \mathrm{d})$ [3-5]. The mean 24-h urinary excretion of $\mathrm{K}$ was $3894 \mathrm{mg}$ for men and $2686 \mathrm{mg}$ for women compared to the EFSA adequate intake of $3500 \mathrm{mg}$ [7]. The mean urinary molar Na:K was 1.90 for men and 2.15 for women. When assessing compliance with target molar ratios, $31 \%$ of men and $25 \%$ of women had a urinary $\mathrm{Na}: \mathrm{K} \leq 1.0$, while $60 \%$ of men and $57 \%$ of women had a molar $\mathrm{Na}: \mathrm{K} \leq 2.0$.

\subsection{Dietary Data}

\subsubsection{Dietary Intakes of Sodium and Potassium}

Mean dietary intakes of sodium (excluding discretionary salt) and potassium are reported as absolute intakes (mg/d) and corrected for energy intake (mg/10 MJ) for total population 18-90 y and by gender and age group (Table 2). The mean dietary sodium intake was $2877 \mathrm{mg} / \mathrm{d}$ in men and $2134 \mathrm{mg} / \mathrm{d}$ in women. There was no difference in sodium intake between men and women in the total population 
after adjusting for energy (men $3022 \mathrm{mg} / 10 \mathrm{MJ}$, women $3077 \mathrm{mg} / 10 \mathrm{MJ}$ ). The mean dietary potassium intake was $3417 \mathrm{mg} / \mathrm{d}$ in men and $2703 \mathrm{mg} / \mathrm{d}$ in women. When adjusted for energy intake, women of all ages had higher potassium intakes than men (men $3621 \mathrm{mg} / 10 \mathrm{MJ}$, women $3897 \mathrm{mg} / 10 \mathrm{MJ}$ ).

Table 1. The $24 \mathrm{~h}$ urinary excretions of sodium, salt and potassium.

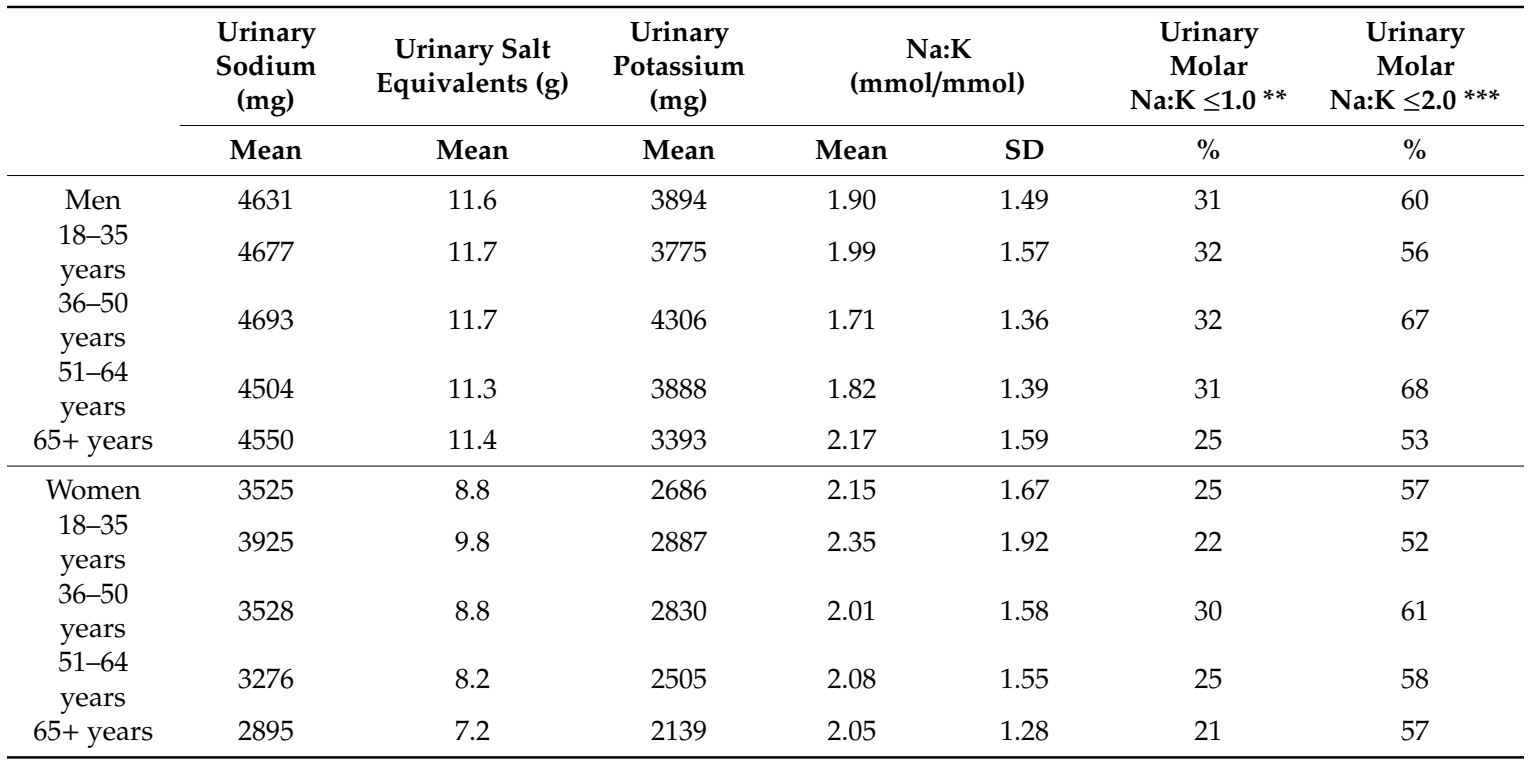

Urinary Na:K (mmol/mmol) and prevalence of urinary Na:K $\leq 1.0$ in Irish adults by age group and gender based on spot urine samples $(n=1121) .{ }^{*}$ Corrected for gender-specific $24-\mathrm{h}$ urine volume estimations derived from a study by Perry et al. (men: $1.97 \mathrm{~L}$; women: $1.67 \mathrm{~L}) .{ }^{* *}$ World Health Organisation $(\mathrm{WHO})$ recommendation (molar Na:K $\left.\leq 1.0\right)$ (WHO guidance on potassium at least $3510 \mathrm{mg}$ per day, on sodium less than $2000 \mathrm{mg}$ per day). ${ }^{* * *}$ Shown to exhibit lower CVD risk.

Table 2. The mean daily intakes of sodium, salt and potassium and dietary molar Na:K in Irish adults $(n=1500)$.

\begin{tabular}{|c|c|c|c|c|c|c|c|c|c|c|c|c|c|c|c|}
\hline & \multirow{3}{*}{$n$} & \multicolumn{4}{|c|}{ Sodium } & \multicolumn{4}{|c|}{ Salt } & \multicolumn{4}{|c|}{ Potassium } & \multirow{2}{*}{\multicolumn{2}{|c|}{$\frac{\text { Dietary Na:K }}{(\mathrm{mmol} / \mathrm{mmol})}$}} \\
\hline & & \multicolumn{2}{|c|}{$\mathrm{mg} / \mathrm{d}$} & \multicolumn{2}{|c|}{$\mathrm{mg} / 10 \mathrm{MJ}$} & \multicolumn{2}{|c|}{$\mathrm{g} / \mathrm{d}$} & \multicolumn{2}{|c|}{$\mathrm{mg} / 10 \mathrm{MJ}$} & \multicolumn{2}{|c|}{$\mathrm{mg} / \mathrm{d}$} & \multicolumn{2}{|c|}{$\mathrm{mg} / 10 \mathrm{MJ}$} & & \\
\hline & & mean & SD & mean & SD & mean & SD & mean & SD & mean & SD & mean & SD & Mean & SD \\
\hline $18-35$ years & 531 & 2687 & 758 & 3053 & 459 & 6.71 & 1.91 & 7.63 & 1.15 & 3036 & 945 & 3450 & 584 & 0.97 & 0.22 \\
\hline $36-50$ years & 437 & 2508 & 733 & 3049 & 452 & 6.27 & 1.85 & 7.63 & 1.13 & 3098 & 873 & 3839 & 650 & 0.88 & 0.20 \\
\hline $51-64$ years & 306 & 2363 & 670 & 2926 & 439 & 5.91 & 1.68 & 7.31 & 1.10 & 3138 & 851 & 3971 & 678 & 0.81 & 0.19 \\
\hline $18-35$ years & 276 & 3073 & 698 & 2988 & 450 & 7.67 & 1.77 & 7.47 & 1.13 & 3522 & 872 & 3432 & 585 & 0.96 & 0.22 \\
\hline $36-50$ years & 205 & 2932 & 671 & 3080 & 454 & 7.33 & 1.70 & 7.71 & 1.14 & 3466 & 853 & 3670 & 608 & 0.92 & 0.21 \\
\hline 51-64 years & 153 & 2671 & 640 & 2925 & 440 & 6.67 & 1.62 & 7.31 & 1.10 & 3402 & 848 & 3768 & 624 & 0.85 & 0.19 \\
\hline $65+$ years & 106 & 2562 & 619 & 3137 & 458 & 6.40 & 1.56 & 7.84 & 1.15 & 3070 & 794 & 3803 & 623 & 0.91 & 0.20 \\
\hline Women & 760 & 2134 & 572 & 3027 & 455 & 5.33 & 1.43 & 7.57 & 1.14 & 2703 & 756 & $3897 *$ & 714 & 0.86 & 0.22 \\
\hline
\end{tabular}

Na intake is estimated from food sources only and does not account for discretionary sources (added at the table or during cooking). ${ }^{*}$ Denotes statistically significant difference $(P<0.001)$ from that of men within the column via a Mann-Whitney $U$ test.

\subsubsection{Dietary Sources of Sodium and Potassium Intake}

The key sources of sodium were 'breads' (22\%), 'cured and processed meat' (18\%), 'soups and sauces' (9\%), 'meat dishes' (7\%), 'vegetables and vegetable dishes' (5\%) and 'milk and yogurt' (5\%) (Figure 1). The key sources of potassium were 'potatoes and potato products' (15\%), 'fresh meat' and 'meat dishes' (13\%), 'milk and yogurt' (13\%), 'fruit and fruit juices' (9\%) 'vegetables and vegetable 
dishes' (8\%), and 'breads' (7\%) (Figure 2). Discretionary salt (i.e., salt added at the table or in cooking) was estimated to account for $30 \%-45 \%$ (range across gender and age groups) of total salt intake.

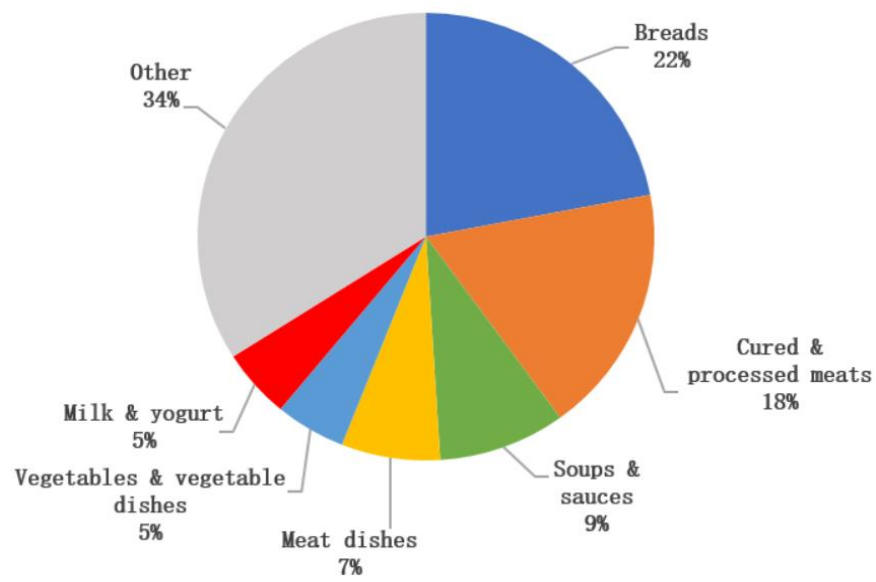

Figure 1. Key sources of sodium intake (excluding discretionary salt) in Irish adults.

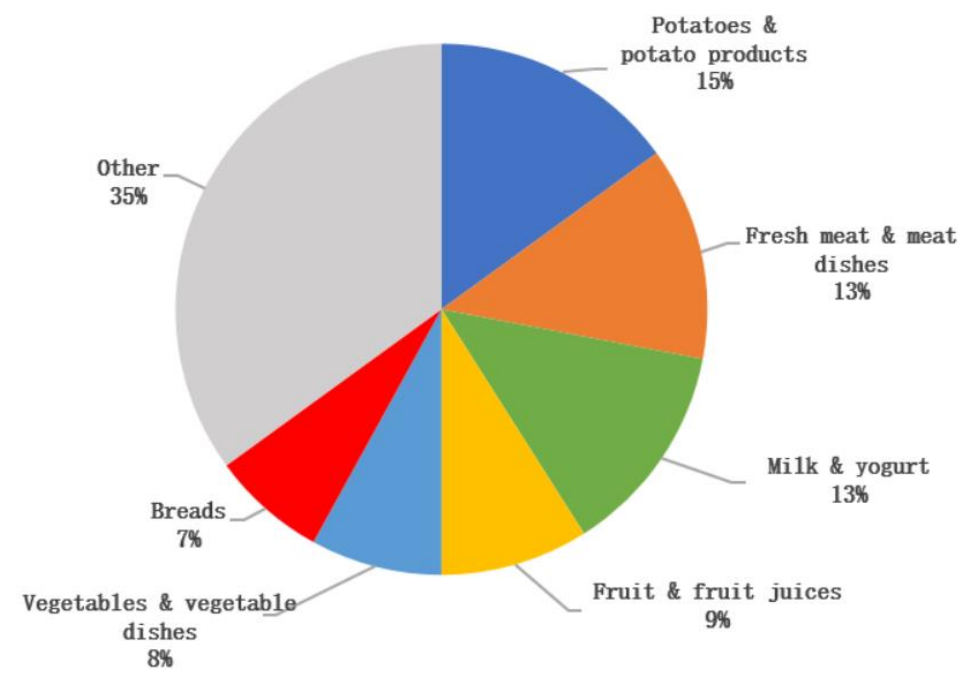

Figure 2. Key sources of potassium intake in Irish adults.

\subsubsection{Foods Associated with A Lower Na:K}

Table 3 reports food group intakes across tertiles of dietary Na:K. Food groups that were negatively associated with a low Na:K were 'breads', 'cured and processed meat' and 'butters, spreading fats and oils'. Food groups that were positively associated with a low Na:K were 'breakfast cereals', 'milk and yogurt', 'potato and potato products', 'vegetables and vegetable dishes', 'fruit and fruit juices', 'fresh meat' and 'nuts and seeds, herbs and spices'. 
Table 3. Dietary intake of sodium, potassium, dietary molar Na:K and food group intakes in Irish adults $(n=1500)$ by tertile of dietary molar Na:K (stratified by age group and gender).

\begin{tabular}{|c|c|c|c|c|c|c|c|}
\hline & \multicolumn{2}{|c|}{$\begin{array}{c}\text { Low } \\
n=499\end{array}$} & \multicolumn{2}{|c|}{$\begin{array}{c}\text { Medium } \\
n=502\end{array}$} & \multicolumn{2}{|c|}{$\begin{array}{c}\text { High } \\
n=499\end{array}$} & \multirow{2}{*}{$\begin{array}{c}P \\
\text { Value }\end{array}$} \\
\hline & Mean & SD & Mean & SD & Mean & SD & \\
\hline Dietary Na:K (mmol/mmol) & 1.0 & 0.2 & 1.4 & 0.2 & 1.9 & 0.3 & 0.000 \\
\hline Mean daily intake of sodium (mg) & 1993 & 705 & 2556 & 782 & 2947 & 938 & 0.000 \\
\hline Mean daily intake of potassium (mg) & 3432 & 1163 & 3112 & 887 & 2621 & 816 & 0.000 \\
\hline \multicolumn{8}{|l|}{ Food group intakes $(\mathrm{g} / \mathrm{d})$} \\
\hline Grains, rice, pasta and savouries & 60.2 & 75.8 & 59.8 & 68.8 & 59.6 & 69.6 & 0.756 \\
\hline Breads & 89.5 & 54.2 & 118.5 & 59.0 & 138.6 & 65.4 & 0.000 \\
\hline Breakfast cereals & 81.5 & 95.2 & 61.4 & 79.4 & 42.8 & 60.7 & 0.000 \\
\hline Biscuits, cakes and pastries & 28.7 & 34.6 & 31.3 & 35.3 & 28.7 & 35.0 & 0.165 \\
\hline Milk & 244 & 213 & 223 & 188 & 163 & 143 & 0.000 \\
\hline Yogurt & 37.8 & 53.7 & 38.6 & 59.0 & 20.5 & 40.6 & 0.000 \\
\hline Creams, ice-creams and chilled desserts & 22.5 & 38.1 & 22.2 & 36.9 & 17.9 & 32.9 & 0.042 \\
\hline Cheeses & 11.0 & 15.4 & 14 & 17.6 & 15.8 & 19.8 & 0.002 \\
\hline Butter, spreading fats and oils & 10.7 & 11.0 & 14.3 & 13.8 & 20.9 & 21.0 & 0.000 \\
\hline Eggs and egg dishes & 15.3 & 23.2 & 15.9 & 21.9 & 18.7 & 25.9 & 0.069 \\
\hline Potatoes and potato products & 138 & 96.5 & 125 & 78.5 & 98.1 & 75.1 & 0.000 \\
\hline Vegetables and vegetable dishes & 132 & 101 & 112 & 72.0 & 98.5 & 68.8 & 0.000 \\
\hline Fruit & 135 & 135 & 95.9 & 109 & 28.8 & 76.6 & 0.000 \\
\hline Fruit juices & 62.3 & 104 & 52.0 & 84.8 & 34.2 & 68.3 & 0.000 \\
\hline Fish and fish dishes & 33.0 & 44.6 & 29.2 & 39.5 & 24.0 & 37.0 & 0.002 \\
\hline Meat and meat dishes & 166 & 96.1 & 181 & 97.2 & 189 & 103 & 0.001 \\
\hline Cured and processed meat & 38.6 & 39.4 & 57.3 & 51.4 & 80.5 & 61.6 & 0.000 \\
\hline Fresh meat & 68.9 & 59.8 & 57.0 & 48.4 & 47.9 & 45.3 & 0.000 \\
\hline Meat dishes & 58.6 & 77.9 & 66.5 & 79.4 & 61.1 & 77.6 & 0.138 \\
\hline Beverages & 1628 & 936 & 1507 & 823 & 1368 & 787 & 0.098 \\
\hline Alcoholic beverages & 351 & 623 & 322 & 589 & 228 & 423 & 0.021 \\
\hline Tea & 449 & 429 & 470 & 403 & 419 & 386 & 0.056 \\
\hline Coffee & 144 & 236 & 117 & 191 & 111 & 207 & 0.016 \\
\hline Other beverages & 683 & 666 & 598 & 609 & 609 & 621 & 0.086 \\
\hline Sugars, confectionery, jams and savoury snacks & 28.7 & 29.9 & 30.2 & 26.4 & 29.7 & 27.8 & 0.201 \\
\hline Soups and sauces & 56.9 & 75.1 & 56.5 & 64.1 & 56.6 & 65.9 & 0.323 \\
\hline Nuts and seeds, herbs and spices & 4.1 & 12.0 & 2.8 & 8.8 & 1.8 & 5.9 & 0.000 \\
\hline
\end{tabular}

$P<0.001$ denotes significance differences across tertile groups via a Kruskal-Wallis test. Note: values in table are based on dietary assessment and do not include measures of discretionary salt.

\section{Discussion}

The aim of this study was to estimate mean 24-h excretions of sodium and potassium (including $\mathrm{Na}: \mathrm{K}$ ) in a nationally representative sample of Irish adults. The mean 24-h urinary $\mathrm{Na}$ excretion was $4631 \mathrm{mg} / \mathrm{d}$ for men and $3525 \mathrm{mg} / \mathrm{d}$ for women, with mean sodium intakes higher than the EFSA AI of $2.0 \mathrm{~g} / \mathrm{d}(5 \mathrm{~g} / \mathrm{d}$ salt) and target maximum population intakes $(<6 \mathrm{~g} / \mathrm{d})$ for all age groups of men and women [3-5]. The mean urinary 24-h K excretion was $3894 \mathrm{mg} / \mathrm{d}$ for men and $2686 \mathrm{mg} / \mathrm{d}$ for women; mean intakes in women of all age groups and men aged $>65$ years were below the AI of $3500 \mathrm{mg} / \mathrm{d}$, while all age groups of younger men ( $<65$ years) had mean intakes above the AI [7]. The key finding from this study was that these high Na and low K excretions resulted in a mean urinary molar Na:K of 1.90 for men and 2.15 for women, with over $72 \%$ of Irish adults exceeding the target urinary molar Na:K of $\leq 1.0$ and almost half ( $41 \%$ ) exceeding a molar Na:K of $\leq 2.0$.

The 24-h urinary sodium and potassium values have been measured in adults in nationally representative surveys in Ireland and the UK (Ireland: Survey of Lifestyle, Attitudes and Nutrition (SLÁN) (2007) and UK: National Diet and Nutrition Survey (NDNS) (2008-2012)) and also in cross sectional studies in Italy, Greece, South Africa, New Zealand, Japan and New York City. The estimated mean daily sodium intakes of adults in Ireland and the UK ranged from 3404 to $4290 \mathrm{mg} / \mathrm{d}$ in men and 2668 to $3040 \mathrm{mg} / \mathrm{d}$ in women [41,45-47], while the estimated potassium intakes ranged from 3128 to $3788 \mathrm{mg} / \mathrm{d}$ in men and 2562 to $3034 \mathrm{mg} / \mathrm{d}$ in women [41,48]. The mean urinary molar Na:K of the adult populations from the cross sectional studies reviewed ranged from 2.2 to 3.8 across studies-greater 
than the target molar ratios of $\leq 1.0$ and $\leq 2.0$ across all population groups [13-18]. Despite variations in methodologies and study samples, these studies suggest that Irish adults have higher sodium and potassium intakes compared to adults in the UK, in addition to a higher mean urinary Na:K than adults in New Zealand, but a lower mean urinary Na:K than adults in Italy, Greece, South Africa, Japan and New York City [13-18].

Successful implementation of strategies to reduce population Na:K may reduce the burden of CVD on public health. The Trials of Hypertension Prevention (TOHP) study estimated sodium and potassium intakes in adults (30-54 years) from multiple 24-h urine collections and analysed CVD occurrence in 10-15 years of post-trial follow up [19]. The findings of this study showed a direct association between Na:K and CVD risk [19], highlighting the potential benefits of any reductions in population Na:K. Similarly, findings from INTERSALT study suggest that a reduction in the mean population urinary $\mathrm{Na}: \mathrm{K}$ from 3.09 to 1.0 would enable a mean reduction in population systolic blood pressure of $3.36 \mathrm{mmHg}$ [9]. It is thought that reductions in population blood pressure of such size (3-5 mmHg) would reduce stroke morality by $8 \%-14 \%$, CHD mortality by 5\%-9\% and all-cause mortality by $4 \%-7 \%$ [9]. Despite some studies reporting a j-shaped relationship between sodium intake and diseases rate $[49,50]$, data from 23 to 26 years of post-trial follow up from the TOHP study found a direct linear relationship between sodium intake and mortality occurrence [51]. The j-shaped relationship found in studies may be explained by measurement bias or reverse causation [52,53], and thus potential adverse health effects due to low sodium intakes at a population level appear unlikely and should not stall efforts to reduce population sodium intakes and Na:K.

The detailed dietary data in the current study allowed us to identify the key dietary sources of sodium and potassium intakes in Irish adults. Key contributors to sodium intakes were primarily processed foods, such as cured and processed meats, breads and soups and sauces, which is similar to the key dietary sources of sodium reported among adults globally [48,53-55]. The key contributors to potassium intakes in Irish adults were similar to that reported in other studies, with potatoes, fresh meat, dairy products and fruits and vegetables commonly reported as key dietary sources of potassium in adults $[48,54,55]$. Of interest, comparison of dietary intakes and urinary excretion values in this study suggests that discretionary salt added at the table or in cooking may account for $30 \%-45 \%$ (range across age groups) of total salt intake in the Irish population. It should be noted that this is a crude estimate for discretionary salt and should be interpreted with caution. However, this should not reduce the importance of implementing strategies to reduce population sodium intakes including that of discretionary salt. Salt reduction programmes such as those in Ireland and the UK have been implemented to achieve gradual, sustained and universal reductions in the salt content of processed and prepared foods such as those identified as key contributors to sodium intakes. These programmes have resulted in significant reductions of up to $60 \%-70 \%$ in the salt content of foods sold in those countries [56,57]. As a result, population salt intakes in these countries have also significantly decreased, with a decrease of over $1.0 \mathrm{~g} / \mathrm{d}$ recorded in the mean salt intake of Irish adults between 2001 and 2011 [58], while a decrease of $0.9 \mathrm{~g} / \mathrm{d}$ was observed in the mean salt intake of adults in the UK between 2000 and 2008 [57]. While the success of such programmes is evident, continued engagement from the food industry is necessary if population target salt intakes are to be achieved. Even slight reductions in the salt content of highly consumed categories of foods can potentially lead to a significant reduction in sodium intakes amongst population groups [4].

This study also investigated food groups that are associated with a higher/lower dietary Na:K in Irish adults, which is a critical step that could aid in strategies to change population-level intakes [53]. The foods positively associated with a lower dietary Na:K were 'breakfast cereals', 'milk and yogurt', 'potato and potato products', 'vegetables and vegetables dishes', 'fruit and fruit juices', 'fresh meat' and 'nuts and seeds, herbs and spices', while the foods negatively associated with a lower dietary $\mathrm{Na}: \mathrm{K}$ were 'breads', 'butters, spreading fats and oils' and 'cured and processed meat'. Efforts to reduce $\mathrm{Na}: \mathrm{K}$ in Irish adults and elsewhere should focus on reducing the consumption of food groups found to be negatively associated with a low $\mathrm{Na}: \mathrm{K}$ and increasing the consumption of the foods found to be 
positively associated with a low Na:K [59]. It is important to note that food groups associated with a lower Na:K are in line with recommendations from the Food-Based Dietary Guidelines (FBDGs) for those in the WHO European region, such as dairy, cereals, vegetables and fruit, while food groups associated with a higher Na:K are those recommended in moderation or with consumption limits such as butters and fat spreads and processed meats. Individual efforts to reduce salt intake have been shown to be often ineffective [60], emphasizing a need for increased population compliance with the FBDGs which are designed to provide advice on foods, food groups and dietary patterns to provide all of the required nutrients in adequate amounts to promote health and prevent chronic diseases. Further efforts to reduce the salt content of products will aid in the reduction of salt intakes and such reductions, along with a parallel increase in the consumption of potassium-rich foods such as fruits and vegetables, may aid in lowering population $\mathrm{Na}: \mathrm{K}[60]$.

The main strengths of this study are that it is based on a nationally representative sample of the Irish population and includes urinary data to complement detailed dietary data for sodium and potassium intake estimates. The detailed dietary intake data were collected at the brand level for each food consumed and sodium values were updated with analytical data on Irish foods. While morning spot urine samples may overestimate sodium excretion and underestimate potassium excretion, appropriate bias correction was applied in this study to estimate the mean Na:K of Irish adults.

\section{Conclusions}

This study provided estimates of Na:K intake in a nationally representative sample of Irish adults. A high sodium intake coupled with low potassium intake (in some age-gender groups) resulted in a mean urinary molar Na:K of 1.90 and 2.15 for Irish men and women, respectively. Consistent with other studies, these estimated Na:K exceed target molar ratios of $\leq 1.0$ and $\leq 2.0$. The key foods found to be positively associated with a lower Na:K were fruits, vegetables, potatoes, breakfast cereals, milk, yogurt and fresh meat, while the foods found to be negatively associated with Na:K were breads, cured and processed meats and butters and fat spreads. Strategies to reduce sodium and increase potassium intakes are necessary in order to lower population $\mathrm{Na}$ K, which may help to reduce the burden of CVD in the Irish population and elsewhere.

Author Contributions: Conceptualisation, A.F. and J.W.; funding acquisition, A.P.N., A.F. and J.W.; investigation, E.M., M.G., L.K. and J.W.; writing-original draft, E.M., M.G., L.K. and J.W.; writing—review and editing, E.M., M.G., L.K., A.P.N., B.A.M., A.F. and J.W. All authors have read and agreed to the published version of the manuscript.

Funding: This research was funded by the Irish Department of Agriculture, Food and the Marine, under the Food for Health Research Initiative 2007-2012.

Conflicts of Interest: The authors declare no conflict of interest. The funders had no role in the design of the study; in the collection, analyses, or interpretation of data; in the writing of the manuscript, or in the decision to publish the results.

\section{References}

1. Perez, V.; Chang, E.T. Sodium-to-potassium ratio and blood pressure, hypertension, and related factors. Adv. Nutr. 2014, 5, 712-741. [CrossRef] [PubMed]

2. WHO. Cardiovascular Disease Fact Sheet; World Health Organization (WHO): Geneva, Switzerland, 2017; Available online: https://www.who.int/cardiovascular_diseases/en/ (accessed on 1 September 2018).

3. EFSA Panel on Nutrition, Novel Foods and Food Allergens (NDA); Turck, D.; Castenmiller, J.; de Henauw, S.; Hirsch-Ernst, K.I.; Kearney, J.; Knutsen, H.K.; Maciuk, A.; Mangelsdorf, I.; McArdle, H.J.; et al. Scientific Opinion on the dietary reference values for sodium. EFSA J. 2019, 17, e05778.

4. FSAI. Salt and Health. Review of the Scientific Evidence and Recommendations for Public Policy in Ireland; Food Safety Authority of Ireland: Dublin, Ireland, 2016.

5. SACN. Salt and Health; The Stationery Office: Norwich, UK, 2003.

6. EFSA. Dietary Reference Values for Nutrients Summary Report. EFSA Support. Publ. 2017, 14. [CrossRef] 
7. EFSA. EFSA NDA Panel (EFSA Panel on Dietetic Products, Nutrition and Allergies); Turck, D.; Bresson, J.-L.; Burlingame, B.; Dean, T.; Fairweather-Tait, S.; Heinonen, M.; Hirsch-Ernst, K.I.; Mangelsdorf, I.; McArdle, H.; et al. Scientific opinion on dietary reference values for potassium. Efsa J. 2016, 14, 56. [CrossRef]

8. Tzoulaki, I.; Patel, C.J.; Okamura, T.; Chan, Q.; Brown, I.J.; Miura, K.; Ueshima, H.; Zhao, L.; Van Horn, L.; Daviglus, M.L.; et al. A nutrient-wide association study on blood pressure. Circulation 2012, 126, 2456-2464. [CrossRef] [PubMed]

9. Stamler, J.; Rose, G.; Stamler, R.; Elliott, P.; Dyer, A.; Marmot, M. INTERSALT study findings. Public health and medical care implications. Hypertension 1989, 14, 570-577. [CrossRef] [PubMed]

10. WHO. Guideline: Sodium Intake for Adults and Children; World Health Organization (WHO): Geneva, Switzerland, 2012.

11. WHO. Guideline: Potassium Intake for Adults and Children; World Health Organization (WHO): Geneva, Switzerland, 2012.

12. Averill, M.M.; Young, R.L.; Wood, A.C.; Kurlak, E.O.; Kramer, H.; Steffen, L.; McClelland, R.L.; Delaney, J.A.; Drewnowski, A. Spot Urine Sodium-to-Potassium Ratio Is a Predictor of Stroke. Stroke 2019, 50, 321-327. [CrossRef] [PubMed]

13. Donfrancesco, C.; Ippolito, R.; Lo Noce, C.; Palmieri, L.; Iacone, R.; Russo, O.; Vanuzzo, D.; Galletti, F.; Galeone, D.; Giampaoli, S.; et al. Excess dietary sodium and inadequate potassium intake in Italy: Results of the MINISAL study. Nutr. Metab. Cardiovasc. Dis. 2013, 23, 850-856. [CrossRef]

14. Vasara, E.; Marakis, G.; Breda, J.; Skepastianos, P.; Hassapidou, M.; Kafatos, A.; Rodopaios, N.; Koulouri, A.A.; Cappuccio, F.P. Sodium and Potassium Intake in Healthy Adults in Thessaloniki Greater Metropolitan Area-The Salt Intake in Northern Greece (SING) Study. Nutrients 2017, 9, 417. [CrossRef]

15. Swanepoel, B.; Schutte, A.E.; Cockeran, M.; Steyn, K.; Wentzel-Viljoen, E. Sodium and potassium intake in South Africa: An evaluation of 24-h urine collections in a white, black, and Indian population. J. Am. Soc. Hypertens. JASH 2016, 10, 829-837. [CrossRef]

16. McLean, R.; Edmonds, J.; Williams, S.; Mann, J.; Skeaff, S. Balancing Sodium and Potassium: Estimates of Intake in a New Zealand Adult Population Sample. Nutrients 2015, 7, 8930-8938. [CrossRef] [PubMed]

17. Asakura, K.; Uechi, K.; Sasaki, Y.; Masayasu, S.; Sasaki, S. Estimation of sodium and potassium intakes assessed by two $24 \mathrm{~h}$ urine collections in healthy Japanese adults: A nationwide study. Br. J. Nutr. 2014, 112, 1195-1205. [CrossRef] [PubMed]

18. Yi, S.S.; Curtis, C.J.; Angell, S.Y.; Anderson, C.A.M.; Jung, M.; Kansagra, S.M. Highlighting the ratio of sodium to potassium in population-level dietary assessments: Cross-sectional data from New York City, USA. Public Health Nutr. 2014, 17, 2484-2488. [CrossRef] [PubMed]

19. Cook, N.R.; Obarzanek, E.; Cutler, J.A.; Buring, J.E.; Rexrode, K.M.; Kumanyika, S.K.; Appel, L.J.; Whelton, P.K. Joint effects of sodium and potassium intake on subsequent cardiovascular disease: The Trials of Hypertension Prevention follow-up study. Arch. Intern. Med. 2009, 169, 32-40. [CrossRef]

20. Iwahori, T.; Miura, K.; Ueshima, H. Time to Consider Use of the Sodium-to-Potassium Ratio for Practical Sodium Reduction and Potassium Increase. Nutrients 2017, 9, 700. [CrossRef]

21. Mente, A.; O’Donnell, M.J.; Dagenais, G.; Wielgosz, A.; Lear, S.A.; McQueen, M.J.; Jiang, Y.; Xingyu, W.; Jian, B.; Calik, K.B.; et al. Validation and comparison of three formulae to estimate sodium and potassium excretion from a single morning fasting urine compared to $24-\mathrm{h}$ measures in 11 countries. J. Hypertens. 2014, 32, 1005-1014, discussion 1015. [CrossRef]

22. Iwahori, T.; Miura, K.; Ueshima, H.; Chan, Q.; Dyer, A.R.; Elliott, P.; Stamler, J. Estimating 24-h urinary sodium/potassium ratio from casual ('spot') urinary sodium/potassium ratio: The INTERSALT Study. Int. J. Epidemiol. 2017, 46, 1564-1572. [CrossRef]

23. Huang, L.; Woodward, M.; Stepien, S.; Tian, M.; Yin, X.; Hao, Z.; Li, Z.; Sun, J.; Yu, Y.; Zhou, B.; et al. Spot urine samples compared with 24-h urine samples for estimating changes in urinary sodium and potassium excretion in the China Salt Substitute and Stroke Study. Int. J. Epidemiol. 2018, 47, 1811-1820. [CrossRef]

24. IUNA. National Adult Nutrition Survey Main Report; Irish Universities Nutrition Alliance: Cork, Ireland, 2011.

25. Cashman, K.D.; Muldowney, S.; McNulty, B.; Nugent, A.; FitzGerald, A.P.; Kiely, M.; Walton, J.; Gibney, M.J.; Flynn, A. Vitamin D status of Irish adults: Findings from the National Adult Nutrition Survey. Br. J. Nutr. 2013, 109, 1248-1256. [CrossRef]

26. Central Statistics Office (CSO). Census 2006 Principal Demographic Results; The Stationery Office: Dublin, Ireland, 2007. 
27. Harrington, K.E.; Robson, P.J.; Kiely, M.; Livingstone, M.B.; Lambe, J.; Gibney, M.J. The North/South Ireland Food Consumption Survey: Survey design and methodology. Public Health Nutr 2001, 4, 1037-1042. [CrossRef]

28. Nelson, M.; Atkinson, M.; Meyer, J. A Photographic Atlas of Food Portion Sizes; Ministry of Agriculture Fisheries and Food: London, UK, 1997.

29. Food Standards Agency. Food Portion Sizes, 3rd ed.; The Stationery Office: London, UK, 2002.

30. Food Standards Agency. McCance and Widdowson's The Composition of Foods, 6th ed.; Royal Society of Chemistry: Cambridge, UK, 2002.

31. Holland, B.; Unwin, I.; Buss, D. Cereal and Cereal Products, Third Supplement to McCance E Widdowson's The Composition of Foods, 4th ed.; HMSO: London, UK, 1988.

32. Holland, B.; Unwin, I.; Buss, D. Milk Products and Eggs. Fourth Supplement to McCance E Widdowson's The Composition of Foods, 4th ed.; HMSO: London, UK, 1989.

33. Holland, B.; Unwin, I.; Buss, D. Vegetables, Herbs and Spices. Fifth Supplement to McCance E Widdowson's The Composition of Foods, 4th ed.; HMSO: London, UK, 1991.

34. Holland, B.; Unwin, I.; Buss, D. Fruits and Nuts, First Supplement to McCance $\mathcal{E}$ Widdowson's The Composition of Foods, 5th ed.; HMSO: London, UK, 1992.

35. Kawasaki, T.; Itoh, K.; Uezono, K.; Sasaki, H. A simple method for estimating $24 \mathrm{~h}$ urinary sodium and potassium excretion from second morning voiding urine specimen in adults. Clin. Exp. Pharmacol. Physiol. 1993, 20, 7-14. [CrossRef]

36. Chan, W.; Brown, J.; Buss, D. Miscellaneous Foods, Fourth Supplement to McCance E Widdowson's The Composition of Foods, 5th ed.; HMSO: London, UK, 1994.

37. Chan, W.; Brown, J.; Lee, S.; Buss, D. Meat, Poultry and Game, Fifth Supplement to McCance E Widdowson's The Composition of Foods, 5th ed.; HMSO: London, UK, 1995.

38. Chan, W.; Brown, J.; Church, S.; Buss, D. Meat Products and Dishes, Sixth Supplement to McCance E Widdowson's The Composition of Foods, 5th ed.; HMSO: London, UK, 1996.

39. Holland, B.; Welch, A.; Buss, D. Vegetable Dishes, Second Supplement to McCance and Widdowson's The Composition of Foods, 5th ed.; HMSO: London, UK, 1996.

40. Black, L.J.; Ireland, J.; Moller, A.; Roe, M.; Walton, J.; Flynn, A.; Finglas, P.M.; Kiely, M. Development of an on-line Irish food composition database for nutrients. J. Food Compos. Anal. 2011, 24, 1017-1023. [CrossRef]

41. Perry, I.; Browne, G.; Loughrey, M.; Harrington, J.; Lutonski, J.; Fitzgerald, A. Dietray Salt Intake and Related Risk Factors in the Irish Population; A Report for Safefood Ireland; Safefood Ireland: Cork, Ireland, 2010; ISBN 987-1-905767-14-4.

42. Iwahori, T.; Ueshima, H.; Torii, S.; Saito, Y.; Kondo, K.; Tanaka-Mizuno, S.; Arima, H.; Miura, K. Diurnal variation of urinary sodium-to-potassium ratio in free-living Japanese individuals. Hypertens. Res. 2017, 40, 658-664. [CrossRef] [PubMed]

43. Tooze, J.A.; Kipnis, V.; Buckman, D.W.; Carroll, R.J.; Freedman, L.S.; Guenther, P.M.; Krebs-Smith, S.M.; Subar, A.F.; Dodd, K.W. A mixed-effects model approach for estimating the distribution of usual intake of nutrients: The NCI method. Stat. Med. 2010, 29, 2857-2868. [CrossRef] [PubMed]

44. Krebs-Smith, S.M.; Kott, P.S.; Guenther, P.M. Mean proportion and population proportion: Two answers to the same question? J. Am. Diet. Assoc. 1989, 89, 671-676.

45. Bates, B.; Cox, L.; Maplethorpe, N.; Mazumder, A.; Nicholson, S.; Page, P.; Prentice, A.; Rooney, K.; Ziauddeen, N.; Swan, G. National Diet and Nutrition Survey: Assessment of Dietary Sodium. Adults (19 to 64 Years) in England, 2014; NatCen: London, UK, 2016.

46. Bates, B.; Cox, L.; Maplethorpe, N.; Mazumder, A.; Nicholson, S.; Page, P.; Prentice, A.; Rooney, K.; Ziauddeen, N.; Swan, G.; et al. National Diet and Nutrition Survey: Assessment of Dietary Sodium. Adults (19-64 years) in Scotland, 2014; Food Standards Scotland: Aberdeen, UK, 2016.

47. Bates, B.; Cox, L.; Maplethorpe, N.; Mazumder, A.; Nicholson, S.; Page, P.; Prentice, A.; Rooney, K.; Ziauddeen, N.; Swan, G.; et al. National Diet and Nutrition Survey: Assessment of Dietary Sodium. Adults (19-64 Years) in Northern Ireland, 2015; Food Standards Agency: Belfast, Ireland, 2016.

48. Bates, B.; Lennox, A.; Prentice, A.; Bates, C.; Page, P.; Nicholson, S.; Swan, G. National Diet and Nutrition Survey. Results from Years 1, 2, 3 and 4 (combined) of the Rolling Programme (2008/2009-2011/2012); Public Health England: London, UK, 2014. 
49. O’Donnell, M.; Mente, A.; Rangarajan, S.; McQueen, M.J.; Wang, X.; Liu, L.; Yan, H.; Lee, S.F.; Mony, P.; Devanath, A.; et al. Urinary sodium and potassium excretion, mortality, and cardiovascular events. N. Engl. J. Med. 2014, 371, 612-623. [CrossRef]

50. Kalogeropoulos, A.P.; Georgiopoulou, V.V.; Murphy, R.A.; Newman, A.B.; Bauer, D.C.; Harris, T.B.; Yang, Z.; Applegate, W.B.; Kritchevsky, S.B. Dietary sodium content, mortality, and risk for cardiovascular events in older adults: The Health, Aging, and Body Composition (Health ABC) Study. JAMA Intern. Med. 2015, 175, 410-419. [CrossRef]

51. Cook, N.R.; Appel, L.J.; Whelton, P.K. Sodium Intake and All-Cause Mortality Over 20 Years in the Trials of Hypertension Prevention. J. Am. Coll. Cardiol. 2016, 68, 1609-1617. [CrossRef]

52. Cobb, L.K.; Anderson, C.A.; Elliott, P.; Hu, F.B.; Liu, K.; Neaton, J.D.; Whelton, P.K.; Woodward, M.; Appel, L.J. Methodological issues in cohort studies that relate sodium intake to cardiovascular disease outcomes: A science advisory from the American Heart Association. Circulation 2014, 129, 1173-1186. [CrossRef]

53. Anderson, C.A.M.; Appel, L.J.; Okuda, N.; Brown, I.J.; Chan, Q.; Zhao, L.; Ueshima, H.; Kesteloot, H.; Miura, K.; Curb, J.D.; et al. Dietary sources of sodium in China, Japan, the United Kingdom, and the United States, women and men aged 40 to 59 years: The INTERMAP study. J. Am. Diet. Assoc. 2010, 110, 736-745. [CrossRef]

54. RIVM. Dutch National Food Consumption Survey 2007-2010. Part 8-A Sources of micronutrients, Version 2, based on dataset DFC_2010_core_20120822; RIVM: Bilthoven, The Netherlands, 2012.

55. Hasenegger, V.; Rust, P.; König, J.; Purtscher, A.E.; Erler, J.; Ekmekcioglu, C. Main Sources, Socio-Demographic and Anthropometric Correlates of Salt Intake in Austria. Nutrients 2018, 10, 311. [CrossRef] [PubMed]

56. FSAI. Salt Reducing in Processed Foods—Salt in Diet Still High. Available online: https://www.fsai.ie/news_ centre/press_releases/salt_reduction_programme_031116.html (accessed on 1 May 2019).

57. Wyness, L.; Butriss, J.; Stanner, S. Reducing the population's sodium intake: The UK Food Standards Agency's Salt Reduction Programme. Public Health Nutr. 2011, 15, 254-261. [CrossRef] [PubMed]

58. FSAI. Irish Adults have Decreased Daily Salt Intake by more than 1 Gram; FSAI: Dublin, Ireland, 2011.

59. FSAI. Scientific Recommendations for Healthy Eating Guidelines in Ireland. Food Safety Authority or Ireland, Dublin; FSAI: Dublin, Ireland, 2011.

60. Okuda, N.; Stamler, J.; Brown, I.J.; Ueshima, H.; Miura, K.; Okayama, A.; Saitoh, S.; Nakagawa, H.; Sakata, K.; Yoshita, K.; et al. Individual efforts to reduce salt intake in China, Japan, UK, USA: What did people achieve? The INTERMAP Population Study. J. Hypertens. 2014, 32, 2385-2392. [CrossRef] [PubMed] 